\title{
The COVID-19 Emergency Response Should Include a Mental Health Component
}

\author{
Shervin Assari, MD, MPH${ }^{1}$; Parham Habibzadeh, $\mathrm{MD}^{2 *}$ \\ ${ }^{1}$ Charles R Drew University of Medicine and Science, Los Angeles, CA, USA \\ ${ }^{2}$ Persian BayanGene Research and Training Center, Shiraz University of Medical Sciences, Shiraz, Iran
}

$\mathrm{W}$ ith an exponential increase in the number of individuals affected worldwide, the coronavirus disease (COVID-19) epidemic has become a significant threat to the global economy and public health. ${ }^{1-2}$ In an attempt to contain the outbreak, and in line with the WHO recommendations, about 50 million people were quarantined in China. ${ }^{3}$ While institution of quarantine was inevitable, mental health needs of the quarantined populations should not be overlooked.

Quarantine suddenly disrupts social connectedness, daily routines, and access to resources, all core to human mental health. These all impose tremendous stress on those in quarantine; the elderly and those with underlying psychiatric disorders are most vulnerable. ${ }^{4}$ In an investigation highlighting this devastating toll on the people placed in quarantine during the severe acute respiratory syndrome (SARS) global outbreak, findings suggestive of posttraumatic stress disorder and depression were seen in $28.9 \%$ and $31.2 \%$ of the studied population, respectively. ${ }^{5}$

In addition to psychological distress and hopelessness, individuals under quarantine may experience mistrust in their health care system, as well as the government. Such feelings may especially arise due to fake news and conspiracy theories that circulate as a result of socialmedia "infodemic", particularly in areas with low social capital and public trust. ${ }^{6}$ Such perceptions may reduce compliance with the recommendations that are necessary to contain the spread of COVID-19, through oppositional and defiant behaviors of the skeptical individuals.

The COVID-19 outbreak has already fueled significant fear in the public. Media has widely shared messages on the fatality and the extreme high risk of acquiring the virus. This high level of fear may hinder adherence to effective preventive behaviors that are necessary for infection control. It also provides a fertile ground for the development of a wide range of unhealthy coping behaviors (to deal with stress) such as binge drinking, binge eating, smoking, and aggression, all of which have long-term consequences. ${ }^{7}$

Furthermore, healthcare workers fighting the outbreak will eventually be exhausted due to long working hours; this situation is aggravated when shortage of personal protective equipment, particularly in countries with limited resources, puts them in stressful situations. Prior experience with previous outbreaks has shown higher levels of psychological distress, post-traumatic stress and burnout among healthcare workers responsible for treatment of SARS patients during the 2003 outbreak. $^{8}$

Unfortunately, emergency responses have historically overlooked the mental health needs of the affected populations. The current response to the COVID-19 crisis is incomplete unless we include a mental health component. Our inaction is costly as it exposes millions of people to psychological sequelae that may persist after the containment of the outbreak when the virus is no longer a threat. Hereby, we hope to raise awareness among the policymakers and health care providers who are involved in the response to the COVID-19 outbreak, locally and globally.

\section{Authors' Contribution}

Both authors have contributed to writing the draft and revising it. Both authors approved the final version.

\section{Conflict of Interest Disclosures}

None to declare.

Ethical Statement

Not applicable.

\section{Acknowledgments}

We would like to thank Dr. Babak Moazen from the Heidelberg Institute of Global Health for his invaluable comments.

\section{References}

1. Wang FS, Zhang C. What to do next to control the 2019-nCoV epidemic? Lancet. 2020;395(10222):391-393. doi: 10.1016/ S0140-6736(20)30300-7.

2. Habibzadeh P, Stoneman EK. The Novel Coronavirus: A Bird's Eye View. Int J Occup Environ Med. 2020;11(2):65-71. doi: 10.15171/ijoem.2020.1921.

3. Wuhan, China, and at least 15 other cities have been 
quarantined as China attempts to halt the spread of the coronavirus. That's about 50 million people on lockdown; 2020. Available from: https://www.businessinsider.com/ wuhan-coronavirus-officials-quarantine-entire-city-2020-1 . Accessed February 7, 2020.

4. Hudson RB. Lack of Social Connectedness and Its Consequences. Public Policy Aging Rep. 2018;27(4):121-3. doi:10.1093/ppar/prx031

5. Hawryluck L, Gold WL, Robinson S, Pogorski S, Galea S, Styra R. SARS control and psychological effects of quarantine, Toronto, Canada. Emerg Infect Dis. 2004;10(7):1206-12.
6. Shimizu K. 2019-nCoV, fake news, and racism. Lancet. 2020;395(10225):685-6. doi: 10.1016/S0140-6736(20)303573.

7. Soames Job RF. Effective and ineffective use of fear in health promotion campaigns. Am J Public Health. 1988;78(2):163-7. doi: 10.2105/ajph.78.2.163.

8. Maunder RG, Lancee WJ, Balderson KE, Bennett JP, Borgundvaag B, Evans S, et al. Long-term psychological and occupational effects of providing hospital healthcare during SARS outbreak. Emerg Infect Dis. 2006;12(12):1924-32. doi: 10.3201/eid1212.060584

Received: March 3, 2020, Accepted: March 21, 2020, ePublished: April 1, 2020

Cite this article as: Assari S, Habibzadeh P. The COVID-19 emergency response should include a mental health component. Arch Iran Med. 2020;23(4):281282. doi: 10.34172/aim.2020.12.

(c) (1) (C) 2020 The Author(s). This is an open-access article distributed under the terms of the Creative Commons Attribution License (http://creativecommons. org/licenses/by/4.0), which permits unrestricted use, distribution, and reproduction in any medium, provided the original work is properly cited. 